\title{
RADIOCARBON CALIBRATION AND APPLICATION TO GEOPHYSICS, SOLAR PHYSICS, AND ASTROPHYSICS
}

\author{
Paul E Damon • Alexei N Peristykh \\ Department of Geosciences, Gould-Simpson 208, the University of Arizona, Tucson, Arizona 85721 USA. \\ Email: pedamon@geo.arizona.edu; peristy@geo.arizona.edu.
}

\begin{abstract}
This paper includes a brief history of the calibration of the radiocarbon time scale from the first recognition of the necessity of calibration in 1962 to INTCAL 98 . Thirty-six years of effort by dendrochronologists and the ${ }^{14} \mathrm{C}$ community have pushed the tree-ring calibration back to $11,854 \mathrm{yr}$ BP. All of this part of the calibration has been done by high-precision beta counting. Uranium-thorium (U-Th) dating of coral samples coupled with accelerator mass spectrometry (AMS) measurement of ${ }^{14} \mathrm{C}$ has extended a fairly detailed calibration back beyond the Bølling warm episode to 15,000 BP. Earlier than $15,000 \mathrm{BP}$, piecewise linear approximation extends INTCAL98 calibration to 24,200 BP.

Blending 1-, 2-, 3-, 10-, and 20-yr tree-ring samples containing regional and data offsets into a decadal time scale does not make an ideal error and bias free $\Delta^{14} \mathrm{C}$ record. Nevertheless, spectral analysis reveals some statistically significant fundamental frequencies as well as interesting "beat" frequencies and the second harmonic of the around 208-yr cycle that is considered to be solar in origin. Although, some very prominent peaks such as the 88-yr (Gleissberg) are clearly solar in origin, some of the lower frequencies such as of the 512-yr period may have an origin in thermohaline circulation. Thus, INTCAL98 provides useful data for geophysical and solar physics research. Lastly, single year $\Delta^{14} \mathrm{C}$ analysis would be useful for revealing invaluable information for solar physics, astrophysics and geophysics not accessible by decadal data. We provide several examples.
\end{abstract}

\section{History of the Calibration of the Radiocarbon Time Scale}

Hessel de Vries $(1958,1959)$ was the first to provide evidence for preindustrial secular variation of atmospheric ${ }^{14} \mathrm{C}$. His data showed an increase in ${ }^{14} \mathrm{C}$ during what we now refer to as the Maunder Minimum, but an offset was apparent in the comparison of measurement on tree rings from Colorado and Germany. When corrected for isotope fractionation the offset was removed and the combined data demonstrated an increase of about 15\%o during the Maunder Minimum (Lerman et al. 1970). The "De Vries effect" (Damon and Long 1962) was soon confirmed (Broecker and Olson 1959) and it was demonstrated that the De Vries effect wiggles are superimposed on a higher amplitude longer trend (Ralph and Stuckenrath 1960; Suess 1961; Damon et al. 1963). At the same time precise and accurate determinations of the ${ }^{14} \mathrm{C}$ half-life were being made (Mann et al. 1961; Watt et al. 1961; Olsson et al. 1962). A new half-life was confirmed at the 5th Radiocarbon Conference held at the University of Cambridge in 1962 (Godwin 1962). The new half-life of $5730 \pm 40 \mathrm{yr}$ was significantly different from the Libby half-life of $5570 \mathrm{yr}$. The question raised at that conference was how to report dates in the future.

The first author (PED) attended that conference and he pointed out the problem in agreeing on the value of the curie, which was tied to the disintegration rate of a gram of radium. At each conference someone had determined a new disintegration rate. After numerous conferences, it was agreed to detach the curie from the activity of radium and arbitrarily fix it at $3.7 \times 10^{10} \mathrm{dps}$. The senior author could visualize the confusion of reporting ${ }^{14} \mathrm{C}$ dates with a new half-life and setting precedent for future changes when it was clear that, even with the new half-life, ${ }^{14} \mathrm{C}$ years would not be exactly equal to calendar years! It seemed best to retain the Libby half-life and make the best correction to the calendar years available at the time of publication. Fortunately, there was general agreement on this procedure and the announcement by Godwin (1962) made it official. The importance of calibration became very evident.

By the time of the 12th Nobel Symposium, which was held 11-15 August 1969 (Olsson 1970) a 7484-yr bristlecone pine chronology had been developed by Ferguson and the ${ }^{14} \mathrm{C}$ trend curve had been extended by the Arizona and Pennsylvania laboratories back to the beginning of the 5th century 
$\mathrm{BC}$ showing that ${ }^{14} \mathrm{C}$ dates with the Libby half-life were about 800 yr younger than calendar years. The new half-life would correct for only $180 \mathrm{yr}$ of the discrepancy. In addition, the three major causes of atmospheric ${ }^{14} \mathrm{C}$ fluctuation had been identified. These were: 1) changes in the intensity of the geomagnetic dipole moment, 2) heliomagnetic modulation, i.e., modulation by the magnetic field imbedded in the solar wind, and 3) changes in the carbon cycle. A prescient article by Lingenfelter and Ramaty (1970) also included the production of ${ }^{14} \mathrm{C}$ by solar flares and supernova.

Two plates were included showing the available and reasonably reliable calibration data. Plate I included only the La Jolla data back to around $2200 \mathrm{BC}$ showing what would later be referred to as the Suess wiggles (De Vries effect) with a calibration curve drawn by eye with his famous "Cosmic Schwung". The second was a plot of all the other data. The Arizona, Groningen, and Pennsylvania laboratories data were published in the symposium volume. All of these were normalized to the international standard NBSI. In addition, the data from Cambridge, Copenhagen, and Heidelberg (Willis et al. 1960), for tree rings from AD 659 to 1859, were included. Incidentally, their paper was the first to suggest a 200 -yr cycle. The publication of this data gave rise to many smoothed and wiggly calibration curves. Actually, these calibration curves were adequate enough to justify Renfrew's (1973) declaration of a second revolution in ${ }^{14} \mathrm{C}$ dating. The first occurred when ${ }^{14} \mathrm{C}$ dating proved the greater antiquity of the European and Near East Neolithic period, setting its beginning some $3000 \mathrm{yr}$ earlier than previously hypothesized within the traditional "short chronology". ${ }^{14} \mathrm{C}$ dating was instrumental in introducing a long chronology. The second revolution took place when the calibration of dates obtained on archaeological materials indicated that the European cultures did not postdate the Middle Eastern cultures as the diffusionists predicted. The second revolution was harder to accept than the first. A third revolution occurred with the advent of the determination of ${ }^{14} \mathrm{C}$ by accelerator mass spectrometry (AMS) in 1977 (Nelson et al. 1977; Bennett et al. 1977). The new technique would make possible the ${ }^{14} \mathrm{C}$ dating of sub-milligram samples of ${ }^{14} \mathrm{C}$ and more rapid analysis. This allowed for greater selectivity in sampling and the dating of minute samples that cannot be dated by beta counting. Nevertheless, calibration by beta counting would continue because of the high precision obtainable with sufficiently large samples.

During the subsequent decade following the 12th Nobel symposium a dozen or so calibration schemes were published. This resulted in considerable confusion in the literature. Consequently, the National Science Foundation (NSF) funded a workshop held in Tucson during the winter of 1979. The purpose was to arrive at a single ${ }^{14} \mathrm{C}$ calibration scheme involving graphs and tables. Twentyone people attended including representatives of laboratories funded by the NSF, dendrochronologists and statisticians. Although the De Vries effect had been amply verified for the last millennium, no single De Vries fluctuation or "Suess wiggle" had been confirmed by two or more laboratories prior to the last millennium. Consequently, a second goal was to verify the Suess wiggles prior to the last millennium. This was particularly important because of the significance of the De Vries effect for solar physics (Damon et al. 1980).

There was clear evidence of the continuation of the "Suess wiggles" (De Vries effect) back to 5000 BC. All but a few of the larger "Suess wiggles" were confirmed. However, although four of the laboratories calibrated to the NBS oxalic acid international standard agreed within $\pm 0.3 \%$ o $( \pm 2.5 \mathrm{yr})$ of the average of the four (Arizona, Groningen, Pennsylvania, and Yale), one laboratory (La Jolla) that calibrated to a laboratory standard diverged from the average by $6 \%$ ( $49 \mathrm{yr}$ too old). Consequently, a correction was required (Klein et al. 1980).

Details of the resultant calibration are given in Klein et al. (1982). The calibration was based on 1154 sampler of dendrochronologically dated wood from the five laboratories previously mentioned. The 
calibration was presented both as graphs and as a table with ${ }^{14} \mathrm{C}$ dates every $10 \mathrm{yr}$ and $95 \%$ confidence ranges for 6 different measurement standard deviations. This calibration scheme served for only $6 \mathrm{yr}$. Beginning with Pearson et al. (1977) and De Jong et al. (1979), a shift had begun to higher precision calibration about $\pm 2 \%$ o. The first calibration issue of Radiocarbon (Stuiver and Kra 1986) included high precision data from six laboratories (Arizona, Belfast, Groningen, Heidelberg, Pretoria, and Seattle) and a computerized ${ }^{14} \mathrm{C}$ age calibration (Stuiver and Reimer 1986). Measurements on dendrochronologically dated German oak and US bristlecone pine extended the calibration back to 7200 $\mathrm{BC}(9150 \mathrm{BP})$. A more detailed account of the history of calibration of ${ }^{14} \mathrm{C}$ dates by dendrochronology through the first calibration issue in 1986 may be found in Damon (1987).

The second calibration issue of Radiocarbon (Long et al. 1993) included an attempt to push the German oak and pine chronology back to 11,400 BP (Becker 1993), corrections to the Belfast ${ }^{14} \mathrm{C}$ data (Pearson and Qua 1993) and to the Seattle data (Stuiver and Becker 1993), plus comparison of AMS measurement of ${ }^{14} \mathrm{C}$ and thermal ionization mass spectrometry (TIMS) measurements of ${ }^{230} \mathrm{Th}$ and ${ }^{234} \mathrm{U}$ on coral to provide a first-order calibration of the ${ }^{14} \mathrm{C}$ time scale back to $30,000 \mathrm{yr}$ (Bard et al. 1993). A controversial shift of 20 yr older in the Belfast data resulted from the removal of two standards that were suspect. The correction in the Seattle data for radon was time dependent resulting in an age increase of only $10{ }^{14} \mathrm{C}$ yr for samples a few hundred years old, an increase of $30 \mathrm{yr}$ for 4500 yr-old samples. Fortunately, careful records were maintained which permitted accurate corrections to be made. The first-order calibration of the ${ }^{14} \mathrm{C}$ time scale by $\mathrm{U} / \mathrm{Th}-{ }^{14} \mathrm{C}$ measurements on coral was a new very important development. ${ }^{14} \mathrm{C}$ dates were shown to be too young by $4600 \pm 600(2 \sigma) \mathrm{yr}$ at $30,000 \mathrm{yr}$ or a depletion of about $550 \%$. The authors point out that this confirms paleomagnetic evidence for a very low dipole field intensity at that time. However, they estimate that $10-20 \%$ of the discrepancy between the two chronometers may involve changes in the carbon cycle.

The Calibration 1993 issue of Radiocarbon was followed 5 yr later by the INTCAL98 calibration issue of Radiocarbon (Stuiver and Van der Plicht 1998). The most significant development in the dendrochronologic calibration of the ${ }^{14} \mathrm{C}$ time scale was in the Hohenheim oak chronology (Spurk et al. 1998) that was found to be in significant error prior to $5242 \mathrm{BC}$ (pre-7192 BP). Correction of these errors resulted in a shift toward older ages of 41-yr pre-5242 BC (pre-7192 BP) and a shift of 95 year $(41+54)$ pre-7792 (pre-9742 BP). Thus, after much labor over $40 \mathrm{yr}$, an improved dendrochronologically dated time scale was being forged.

However, as has been said, "the devil is in the details". It has become increasingly apparent that a global ${ }^{14} \mathrm{C}$ time scale accurate to better than $\pm 50 \mathrm{yr}$ is not possible due to hemispheric and regional offsets. A short review of the literature on this subject was given by Stuiver et al. (1998:1045-6). Three processes have been reported to produce a measurable regional change in the ${ }^{14} \mathrm{C} / \mathrm{C}$ ratio of the atmosphere. There is a latitude effect (Braziunas et al. 1995), costal upwelling (Damon et al. 1989, 1999; Damon 1995) and thawing of frozen earth (Damon et al. 1996). The latitude effect is negligible from the Equator to the Arctic Circle but increases from the equator to around $65^{\circ} \mathrm{S}$ where it has been calculated to be $-6 \%$ ( $50 \mathrm{yr}$ too old) (Braziunas et al. 1995).

However, in regions of coastal upwelling, such as western South Africa, depletion can be greater than the predicted latitude effect. More or less strong westerly winds result in an Ekman spiral (Kennett 1982). The spiral upon reaching the coast of Southern Africa results in the strong Benguela current that produces divergence and upwelling of deepwater rich in nutrients and ${ }^{14} \mathrm{C}$-depleted $\mathrm{CO}_{2}$. If the upwelling is sufficiently strong and continuous it can reduce the ${ }^{14} \mathrm{C} / \mathrm{C}$ ratio in the prevailing air mass sufficiently enough for the depletion to be measured in tree rings. So far, we have measured 44 $( \pm 3 \%$ ) single-year tree rings of Widdringtonia cedarbergensis from Die Bose, Cape, South Africa 
(Damon et al. 1999). These measurements are compared with the same years from trees (4 Douglasfirs and 1 Noble fir) growing in the Pacific Northwest (Stuiver et al. 1998). The results from 1794 to 1829 are in close agreement with the predicted latitude effect of $2.9 \pm 0.5 \%$. However, following 1829 there is a rapid decrease to very low values with an average depletion for the $8 \mathrm{yr}$ from 1830 to 1837 of $9.4 \pm 0.8 \%$ o ( $78 \pm 7 \mathrm{yr}$ ). The latitude effect alone would only account for about a $24-\mathrm{yr}$ decrease in age. However, the frame of reference is to the Pacific Northwest where coastal upwelling also takes place (Kennett 1982). The climatic implications are interesting but detailed discussion is beyond the scope of this paper.

Data published by Vogel et al. (1993) in Calibration 1993 show that depletion in excess of the latitude effect continued until 1890 after which the situation is complicated by the Suess effect. Their data from 1853-1890 show a depletion of $5.5 \pm 0.6 \%$ o compared to the predicted latitude effect of $3.1 \pm$ $0.5 \%$ leaving an excess due to upwelling of $2.4 \pm 0.8 \%$. Thus, upwelling significant enough to deplete the prevailing air masses in ${ }^{14} \mathrm{C}$ continued from 1830 to 1890 or a duration of $60 \mathrm{yr}$. As a consequence, westerly winds must have driven the Ekman spiral and Benguela current more intensely.

Another very significant aspect of INTCAL98 is further contributions to the extension of the ${ }^{14} \mathrm{C}$ time scale by U/Th and ${ }^{14} \mathrm{C}$ measurements on coral. There is good agreement between the tree-ring and coral data with the corrected dendrochronology. Bard et al. (1998) point out that ages beyond U/ Th calibrated 10,000 BP including the two points at U/Th age 41,100 $\pm 50 \mathrm{BP}$ and 30,230 $\pm 160 \mathrm{BP}$ can be approximated by a simple linear equation: $[\mathrm{cal} \mathrm{BP}]=1.168 \times\left[{ }^{14} \mathrm{C}\right.$-age $\left.\mathrm{BP}\right]$. A second-order polynomial provides a better fit. Significant fluctuations from a linear trend can be seen in the coral data of Bard et al. (1998) and Burr et al. (1998). Figure 5 of Burr et al. (1998) shows unacceptable divergence between the tree-ring data and varve data from Sweden (Wohfarth 1996) and Lake Gościąż in Poland (Goslar et al. 1995) but much closer agreement with Cariaco marine varve data (Hughen et al. 1998). Because of this, only the Cariaco varve data were included in INTCAL98. The various corrections and adjustments necessary to arrive at the INTCAL data base are described in detail by Stuiver et al. (1998). The resultant data merged in decadal intervals and presented in per mil differences are shown in Figure 1 below. Terrestrial varve chronologies are planned to be discussed in a future calibration issue of Radiocarbon.

\section{Calibration Curve and its Fine Structure}

The $\Delta^{14} \mathrm{C}$ versus calendar age in Figure 1 can be divided into three parts. Prior to $9846 \mathrm{BC}$, the curve is dependent on the coral data and varve data from the Cariaco Basin. Prior to $5242 \mathrm{BC}$ there are significant changes in the Hohenheim dendrochronology, and after $5242 \mathrm{BC}$, there is no change in the dendrochronology. Work on the $\Delta^{14} \mathrm{C}$ of coral began during the last decade of the 20th century, whereas data using dendrochronologically dated tree rings has been obtained over about four decades. The resultant trend is generally considered to be from changes in the intensity of the Earth's dipole moment and the decay of a large inventory of ${ }^{14} \mathrm{C}$ accumulated as a result of a very low average dipole moment during most of the preceding late ice age. However, Stuiver et al. (1998) point out that the pronounced minimum of the coral $\Delta^{14} \mathrm{C}$ and pronounced maximum of $\delta^{18} \mathrm{O}$ occurs during the Bølling warm episode. This demonstrates that climate induced changes in the carbon cycle are an important factor during the Ice Age.

The Suess wiggles around the trend have been referred to as the fine structure (Damon et al. 1989). The inset in Figure 1 shows the last millennium of data unfiltered. Observation of sunspots have demonstrated the absence or dearth of sunspots during the Maunder Minimum (Eddy 1976). The absence of sunspots is associated with a much lower solar wind intensity and an increase in the cosmic-ray intensity and consequent neutron flux that produces ${ }^{14} \mathrm{C}$ by the reaction ${ }^{14} \mathrm{~N}(\mathrm{n}, \mathrm{p}){ }^{14} \mathrm{C}$. Thus 
the magnetic field imbedded in the solar wind has an effect similar to the Earth's dipole field intensity. Both deflect cosmic rays from reaching the Earth and so there is both geomagnetic and heliomagnetic modulation of the neutron flux and consequent production of ${ }^{14} \mathrm{C}$ and other cosmogenic isotopes. The relationship with ${ }^{14} \mathrm{C}$ production is the inverse. Low solar activity or dipole field intensity is associated with an increase in ${ }^{14} \mathrm{C}$ production. Consequently, the Maunder Minimum of solar activity results in high $\Delta^{14} \mathrm{C}$ (De Vries effect) during the Maunder Minimum. Other ${ }^{14} \mathrm{C}$ maxima in the fine structure have also been associated with solar activity; these are named after astronomers (Oort, Wolf, Spörer, Maunder, and Dalton). The Oort and Wolf minima are separated by the Medieval Solar Maximum, which is contemporaneous with Lamb's Late Medieval Warm Epoch (Lamb 1965). On the other hand, the Maunder Minimum has been associated with cooler climates by various authors. Consequently, there is the possibility of an irradiance component associated with the ${ }^{14} \mathrm{C}$ Maxima and Minima (Eddy 1977).

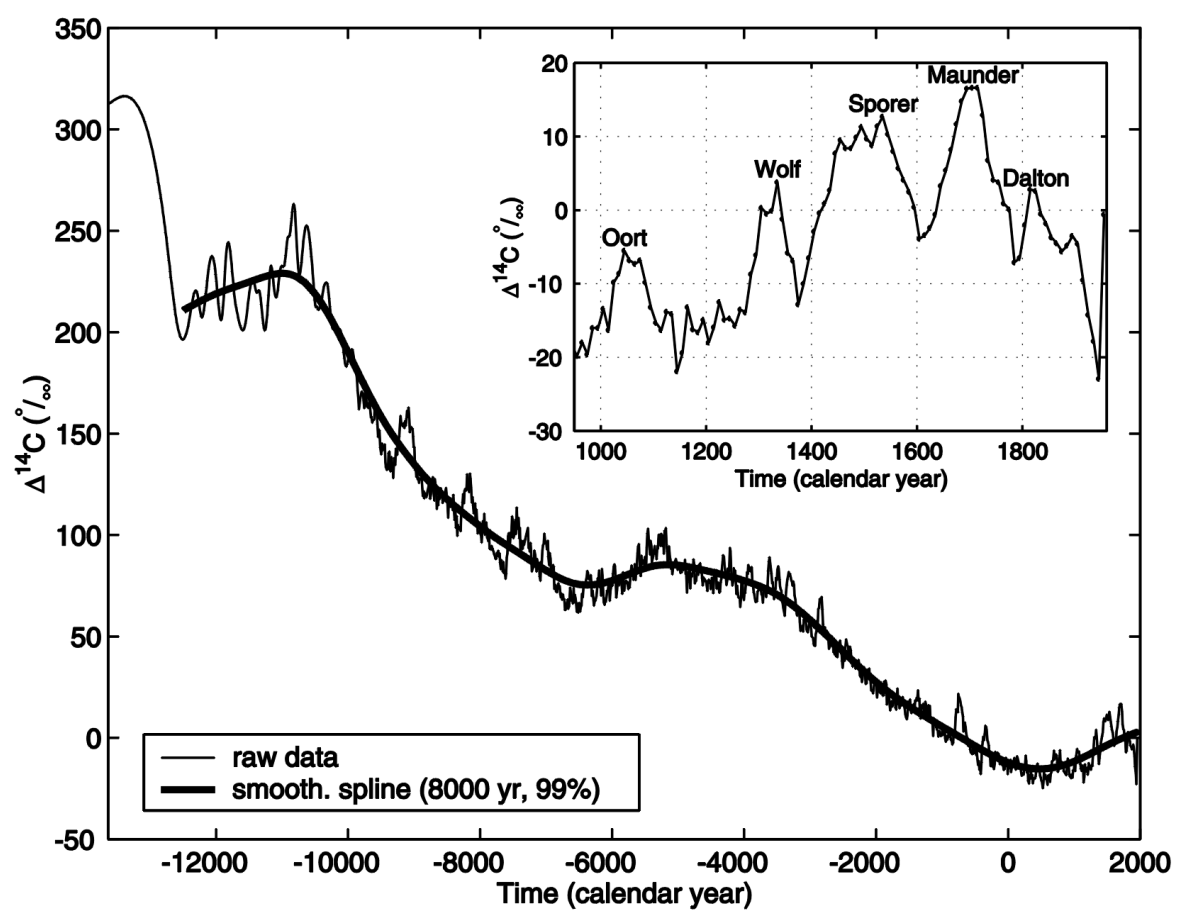

Figure $1 \Delta^{14} \mathrm{C}$ data back to $16,000 \mathrm{BP}$. The curve is based on INTCAL98 tree-ring data back to $11,854 \mathrm{BP}$. Prior to that the curve is based on marine data (coral and varves). The inset shows the unfiltered $\Delta^{14} \mathrm{C}$ data for the last millennium. The $\Delta^{14} \mathrm{C}$ maxima (solar activity minima) are named after unfiltered $\Delta^{14} \mathrm{C}$ data for the 1 st millennium. The $\Delta^{14} \mathrm{C}$ maxima (solar activity minima) are named after astronomers. The Medieval Solar Maximum occurs between the Oort and Wolf Minima of solar activity.

\section{Spectral Analysis of $\Delta^{14} \mathrm{C}$ Variations in the INTCAL98 Data}

The $\Delta^{14} \mathrm{C}$ obtained from coral is not yet at a stage that warrants spectral analysis. The dendrochronologically dated $\Delta^{14} \mathrm{C}$ data extend back to $11,854 \mathrm{BP}$. However, there are still a few gaps in the record prior to $7195 \mathrm{BC}$. Consequently, we confine spectral analysis to the data from $7195 \mathrm{BC}$ to $\mathrm{AD}$ 1895. 
Before analyzing the $\Delta^{14} \mathrm{C}$ data for significant periodicities in the fine structure, some pre-processing is required. It is necessary to remove the long-term trend which is thought to be due to the result of change in the intensity of the geomagnetic dipole moment. To calculate the long-term trend, lowpass filtering is required. For the purpose of low-pass filtering we chose a smoothing spline algorithm (Cook and Peters 1981). This method unlike the cubic interpolating spline, approximates the observational data $\left(y_{i}, i=1, \ldots, n\right)$ with rescaling weights $\delta y_{i}$ through minimizing the following functional (Reinsch 1967):

$$
\int_{x_{1}}^{x_{n}}\left[f^{\prime \prime}(x)\right]^{2} d x
$$

under the constraint

$$
\sum_{i=1}^{n}\left[\frac{f\left(x_{i}\right)-y_{i}}{\delta y_{i}}\right]^{2} \leq S,
$$

where $S$ is some given parameter specifying scaling.

An advantage of this smoothing spline as a digital filter is monotony of its magnitude frequency response, which means it does not have ripples and, therefore, it produces no artificial peaks in Fourier spectrum. Moreover, its magnitude frequency response function can be expressed by a simple formula with only one given parameter which, being changed, defines a family of similar curves intersecting only at zero frequency. Hence, it is uniquely defined by specifying its any single point (except, of course, zero frequency). Therefore, one totally determines all properties of the magnitude spectrum of a smoothing-spline filter by specifying its gain $(G, \%)$ at some period $(T, y r)$ of interest. Another great advantage of this technique is a zero phase shift (phase frequency response is equal everywhere to zero), which means it does not distort the shape of the signal.

The smoothing spline to get long-term trend is determined by parameters $T=8000 \mathrm{yr}, \mathrm{G}=99 \%$. Figure 2 includes the detrended $\Delta{ }^{14} \mathrm{C}$ data distinguishing the low pass components by smoothing spline ( $T=1000 y r, G=99 \%$ ) from higher frequency components.

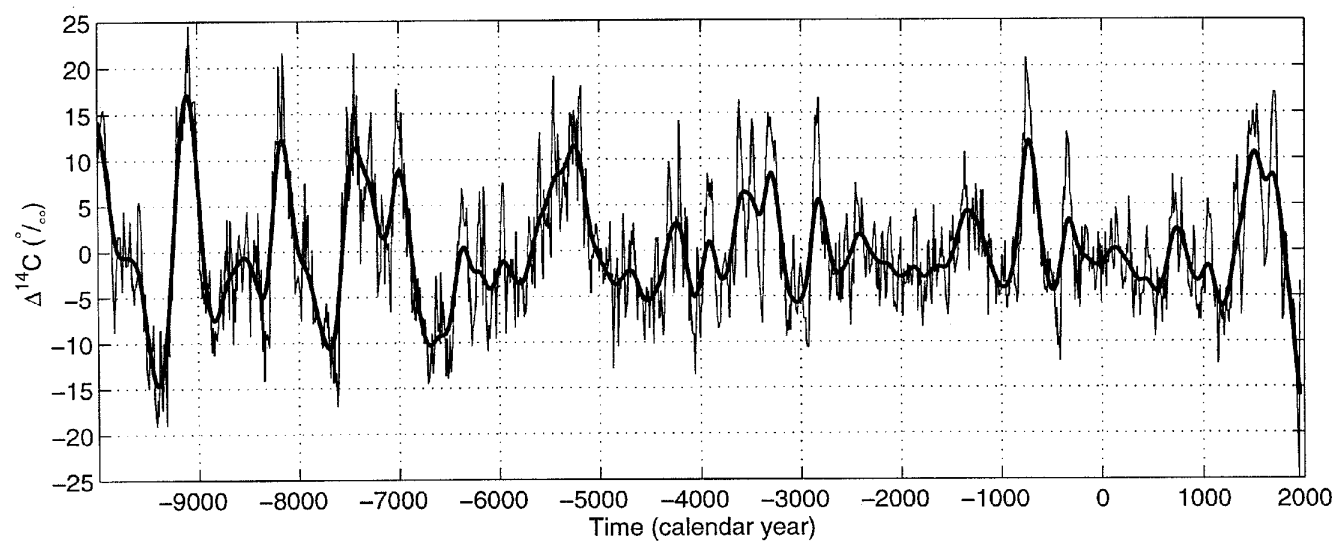

Figure 2 Detrended tree-ring $\Delta^{14} \mathrm{C}$ data (thin line) and further low-pass filtered by a smoothing spline of $T=1000 \mathrm{yr}$, $G=99 \%$ (thick line). 
We used a Welch modified periodogram (Giordano and Hsu 1985) spectral estimator scheme, which uses averaging periodograms of weighted and overlapped data segments of the total record. The purpose of overlapping segments is to increase the number of segments that are averaged for a given data record length $(N)$ and therefore, to decrease the variance of PSD estimate as a statistical variable. To equalize the treatment of most of the data samples, we used symmetric 50\% overlap (for $L=$ $[N / K]$ - long segments that gives us $2 \cdot K-1$ segments). Chosen data windows were applied to the linearly detrended data in each segment prior to the computation of the segment periodogram. The purpose of tapered windowing is to reduce the effect of side lobes and to decrease the estimation bias, at the price of a slight $(<2)$ decrease in resolution. We used a Tukey-Hamming window:

$$
w(x)=\left\{\begin{aligned}
\frac{1}{2}[(1+a)+(1-a) \cdot \cos (2 \pi x / L)], & |x| \leq L / 2 \\
0, & |x|>L / 2
\end{aligned}\right\}
$$

where $a=0.08$ is data weight at the edges of the tapered window. The Tukey-Hamming window was preferred to the Hanning window $(a=0)$ because of its somewhat lower ratio of largest side lobe to main lobe amplitudes ( $-43 d B$ compared to $-32 d B$ ), whereas it has the same main lobe width $8 \pi / \mathrm{L}$ $\mathrm{rad}$ (Cadzow 1987). For the purpose of spectral peaks comparison, we plot spectra here as the square root of spectral power density. Unless otherwise specified, the method used will be the above described Welch's weighted overlapped segment averaging (WOSA) spectral estimator.

It is well established that changes in the "great ocean conveyor belt" (Broecker 1991) resulted in climate instability during the Last Ice Age and consequent changes in the carbon cycle. In contrast, Holocene climate has been relatively stable on a scale of the North Atlantic hydrologic cycle (e.g., see Figure 1 in Dansgaard et al. 1993). However, during the transition period following the Younger Dryas (ca. 9700 BC), the spline data in Figure 2 follows rather large fluctuations of the fine structure. This might suggest significant changes in the carbon cycle modulating ${ }^{14} \mathrm{C}$. However, Figure 14 in Stuiver et al. (1998) shows no reflection in the GISP2 $\delta^{18} \mathrm{O}$ record for the large peak at $9050 \mathrm{BC}$ (see Figure 2 in this paper). Consequently, we will assume that during the Holocene the detrended $\Delta^{14} \mathrm{C}$ data is not dominated by large-scale climate induced changes in the carbon cycle. We will show that changes in solar activity are important as implied by the naming of the $\Delta^{14} \mathrm{C}$ maxima- solar activity minima after astronomers in the inset within Figure 1. This does not preclude a synchronous enhancement of the Maunder-type episodes by a Sun-climate component affecting the transfer of carbon from the mixed layer to deep sea. Stuiver and Braziunas (1993) refer to this as a Sun-ocean contribution to atmospheric $\Delta{ }^{14} \mathrm{C}$. There is a $\Delta^{14} \mathrm{C}$ climate correlation. Damon and Jirikowic (1992) and Stuiver et al. (1997) have shown that small changes in $\delta^{18} \mathrm{O}$ in Greenland ice cores correlate with the $\Delta^{14} \mathrm{C}$ events in Figure 1 inset.

The INTCAL98 calibration curve in Figure 1 is not composed from consecutive decadal samples with the center of each decade spaced by exactly $10 \mathrm{yr}$. Even in decadal data from the same laboratory there are occasional offsets and samples of different length. Single, 3, 10, and 20-yr data were carefully merged into a decadal sequence. For, example bidecadal data were merged into 2 consecutive decades. Corrections for offsets in specific millennial period of time do not exceed 41 yr. Offsets of laboratories from INTCAL98 are typically $\leq 10 \mathrm{yr}$, except for the 4th and 5th millennia BC where a few offsets were greater (ca. 20 yr). We have already discussed hemispheric and regional offsets that can be greater than the above millennial offsets, for example, the 60-yr period from AD 1830 to 1890 for trees affected by upwelling caused by the Benguela current off western South Africa. Some "noise" is unavoidable in INTCAL98 but we believe that the signal processing technique discussed above will minimize that. 


\section{The Results of Spectral Analysis of Decadal Data}

Figure 3 presents the results of Fourier spectral analysis. The prominent peak at $88 \mathrm{yr}$ is the Gleissberg cycle (Gleissberg 1944). We have shown its derivation from sunspot numbers in (Damon and Peristykh 1999). From Figure 1 it can be seen it is very prominent in this record of 9 millennia. We can be certain that its origin is solar. The cycle at $207 \mathrm{yr}$ is inferred to be solar because of its relation to the Maunder Minimum of solar activity and other minima and maxima of ${ }^{14} \mathrm{C}$ production (Damon and Sonett 1991; Stuiver and Braziunas 1993). There may be also a Sun-climate component as previously mentioned. This period seems to modulate the 88-yr Gleissberg cycle (Jirikowic 1993) as can be seen by the "beat" frequency (correspondent period is equal to $1 /(1 / 88-1 / 207) \approx 150 \mathrm{yr}$ ). The 207-yr cycle also has the second harmonic at 104 yr. The Gleissberg cycle appears to be amplitude modulated (AM) by the about 2050-yr Hallstattzeit, as manifested by the two equally spaced side peaks. The Hallstattzeit cycle is enigmatic (Damon and Sonett 1991). At least for the last three little ice ages in central Europe (Schmidt and Gruhle 1988) it appears to act as a gate with 600-yr high $\Delta^{14} \mathrm{C}$ variance preceded and followed by $1500 \mathrm{yr}$ of low $\Delta^{14} \mathrm{C}$ variance (Damon and Jirikowic 1992). Although it produces symmetric side peaks by AM of Gleissberg cycle, such side bands are not observed on both sides of 207-yr cycle. The 207-yr cycle is always accompanied by a $226-$ $232 \mathrm{yr}$ companion in various analyses but never with the significant $192 \mathrm{yr}$ side peak as would be expected from AM by the Hallstattzeit cycle. This needs further investigation.

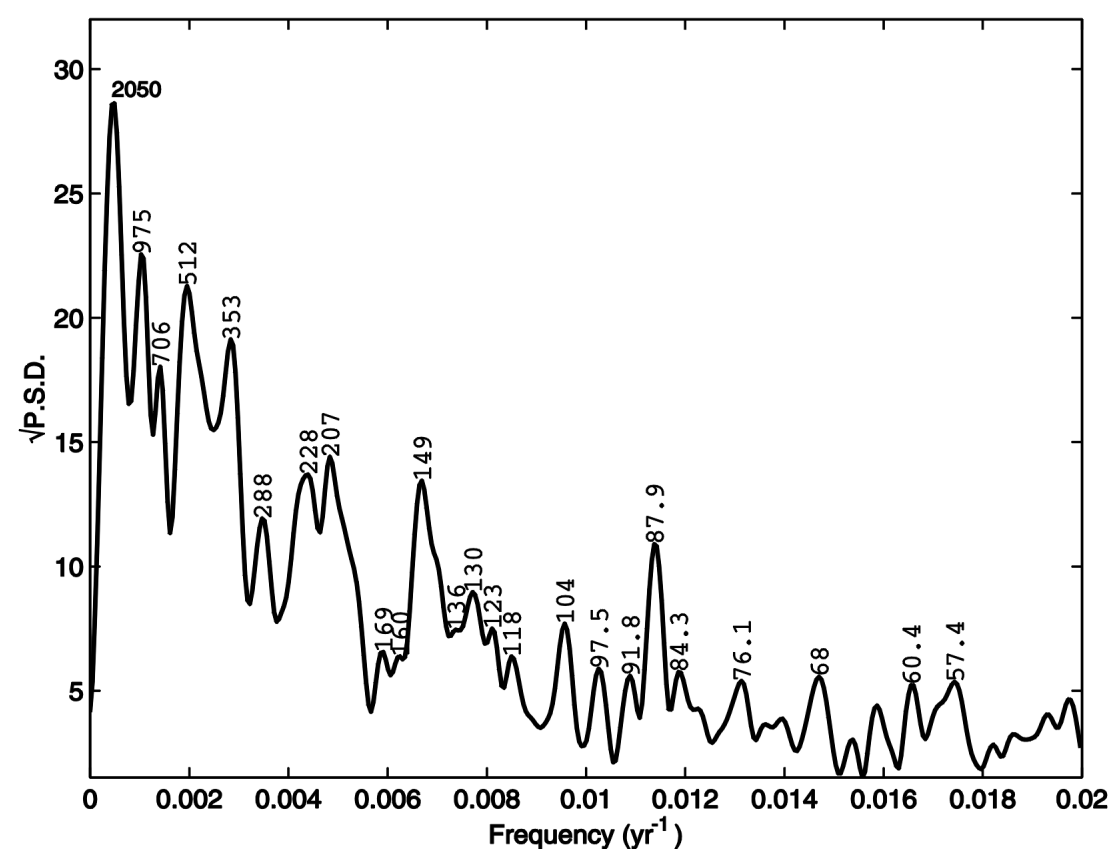

Figure 3 Fourier spectrum of detrended decadal $\Delta^{14} \mathrm{C}$ data. Note the intense 88 -yr Gleissberg cycle with side bands.

Stuiver and Braziunas (1993) relate the 512-yr cycle to flux oscillations in the Atlantic Ocean thermohaline circulation. If this is valid perhaps the Hallstattzeit cycle period is also oceanic in origin from internally induced or externally forced oscillations. Pestiaux et al. (1988) have suggested that $10.3 \pm 2.2,4.7 \pm 0.8$, and $2.5 \pm 0.5$ kyr periods in the Maximum Entropy spectrum of the planktonic 
and benthic foraminifera may be combination tones of the 41,23, and $19 \mathrm{kyr}$ periods in the insolation parameters. Their $\delta^{18} \mathrm{O}$ data covers the Last Ice Age. Two of the cores are from the northern Indian Ocean and a third is from the southern Indian Ocean. Stuiver et al. (1997) examined the $\delta^{18} \mathrm{O}$ record in the GISP2 ice core and found the strongest millennial change to be $1470 \mathrm{yr}$ for the interval from 12,000 to 50,000 BP. One of the cores above is close to the west coast of India. Globorotalia menardii, a deeper water foraminifera from that core, is the only record showing a $1.5 \mathrm{kyr}$ period in the $\delta^{18} \mathrm{O}$ record. The upper water foraminifera, Globigerinoides ruber, shows a $\delta^{18} \mathrm{O}$ peak at $2.6 \mathrm{kyr}$. Upper water foraminifera from the other 2 cores show periodicities of 2.3 and $2.7 \mathrm{kyr}$. Obviously, more work will be required to solve this puzzle.

\section{Hyperfine Structure of the $\Delta^{14} \mathrm{C}$ Secular Variations}

The Nyquist frequency cutoff for decadal data is $0.05 \mathrm{yr}^{-1}$, i.e. periods only longer than $20 \mathrm{yr}$ can be detected by Fourier analysis. The INTCAL98 data has involved accommodation of $20 \mathrm{yr}$ data. Consequently, the resolution is lower than $20 \mathrm{yr}$. Even with single-year data, we are limited by the carbon cycle low-pass filtering. The atmosphere contains an amount of ${ }^{14} \mathrm{C}$ equal to a little more than 100 times the current steady state production rate. Consequently, an increase in production rate of $10 \%$ during one year would only result in an increment of $1 \%$ in atmospheric $\Delta \Delta^{14} \mathrm{C}$. Thus, the atmosphere acts as a low-pass filter such that the shorter the period of a cycle the stronger the attenuation. The attenuation for an 11-yr cycle is about 70 , whereas the change in production rate is about $\pm 10 \%$, consequently the atmospheric $\Delta^{14} \mathrm{C}$ variation would be about $\pm 1.4 \%$. Obviously annual data of high precision are required to observe an atmospheric ${ }^{14} \mathrm{C}$ cycle of this magnitude. Stuiver and Braziunas (1998) report measurement with a precision of $\leq 2 \%$ of 48 single tree rings dendrochronologically dated from 1897-1994. After removing the trend with a cubic spline the average amplitude of the measured about $11 \mathrm{yr}$ (Schwabe) cycle was $\pm 1.25 \%$ o with an average lag time of $1.8 \mathrm{yr}$ in reasonable agreement with theoretical expectation.

Damon et al. (1998) are studying the Medieval Solar Maximum that occurs between the Oort and Wolf Minima. It seems to be the closest analog to the Contemporaneous Solar Maximum (Damon and Jirikowic 1994). Measurements are complete between AD 1065 to AD 1300 with a gap remaining between AD 1200 and AD 1238. The gap occurs because of the difficulty of obtaining samples of adequate weight from very thin tree rings that occur in that time interval. We expect to close the gap this winter. Figure 4 shows the results of Fourier analysis consisting of a Discrete Fourier Transform (DFT) of the detrended data from AD 1065 to AD 1200. The Hale cycle occurs at $21.3 \mathrm{yr}$ and the Schwabe cycle at $10.4 \mathrm{yr}$ with side peaks resulting from modulation by the $88 \mathrm{yr}$ Gleissberg cycle. Four harmonics are also present.

As previously mentioned, Lingenfelter and Ramaty (1970) at the 12th Nobel Symposium discussed the production of atmospheric ${ }^{14} \mathrm{C}$ by supernovae explosions. The detection of such events required high precision and single-year dendrochronologically dated tree rings. Such a record became available in 1981 with a slight revision in 1998 (Stuiver and Braziunas 1993; Stuiver et al. 1998). We searched the data that extended back to AD 1510 and found no evidence for the Tycho Brahe (1572) and Kepler (1604) Supernovae in the data. This is not surprising considering the distance from the Earth of these events (10,000 and 26,000 light-years). For this reason we chose SN1006AD for a pilot study (Damon et al. 1995) because it exploded at a distance of 4000 light-years. Up until recently, it was thought to be the closest supernova to Earth. Recently, a young nearby supernova X-ray remnant has been discovered (Aschenbach 1998). $\gamma$-rays from ${ }^{44} \mathrm{Ti}\left(\mathrm{T}_{1 / 2}=47 \mathrm{yr}\right.$ ) have been observed (Iyudin et al. 1998). Its distance from Earth is estimated to be only about 650 light-years. SN1006AD has been observed to have X-ray, optical, and radio remnants. The remnant is in the form of a shell and it 


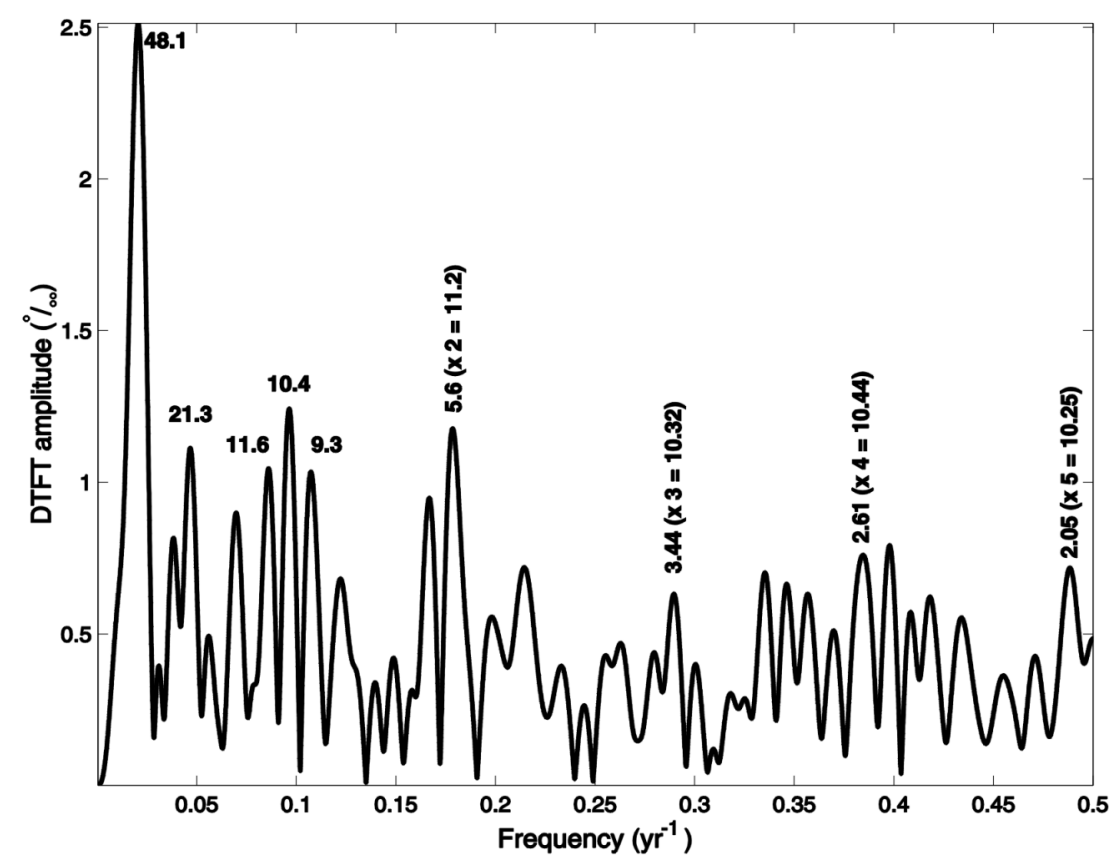

Figure 4 Spectral analysis of single-year data from AD 1065 to AD 1200. The data are from a high-precision $(\leq 2 \%$ ) record obtained with state-of-the-art beta counting.

is a known pulsar. According to theory, acceleration takes place within the remnant at some time after the incandescent explosion producing pions that decay to two hard $(\mathrm{GeV}) \gamma$-rays (Berezinskii and Ginzburg 1990). Upon reaching the Earth, the $\gamma$-rays initiate electron-positron showers. The electrons and positrons have near collisions with atmospheric nuclei emitting bremsstrahlung radiation ( $\gamma$-rays). The bremsstrahlung $\gamma$-rays are ultimately degraded until they fall into a "giant" $\gamma$-n, $\gamma$ - $2 \mathrm{n}$ cross-section between 10 and $40 \mathrm{MeV}$. The emitted neutrons are fast but about two thirds are thermalized producing ${ }^{14} \mathrm{C}$ that oxidizes to ${ }^{14} \mathrm{CO}_{2}$ and participates in the $\mathrm{C}-\mathrm{O}$ cycle.

We measured the cellulose in tree rings before and after the arrival of light from SN1006AD and have found a distinct pulse (Figure 5) beginning after AD 1008 with a very fast rise time to a maximum between AD 1011-1015. Following AD 1015 the pulse decays as it equilibrates with the biosphere and ocean mixed layer. By AD 1021, $\Delta^{14} \mathrm{C}$ starts rising to the Oort $\Delta^{14} \mathrm{C}$ Maximum, which occurs a little over $20 \mathrm{yr}$ later. The peak height of SN1006AD event is $8 \%$. A $\Delta^{14} \mathrm{C}$ event from a single enormous solar flare would have a fast rise time but would begin to decay sooner than after the 4-yr maximum. A series of solar flares would not have as fast a rise time. We suggest that this is a unique $\Delta^{14} \mathrm{C}$ event and no coincidence that it begins only $2 \mathrm{yr}$ after the light from SN1006AD first arrived on 30 April 1006 (Murdin 1985). 


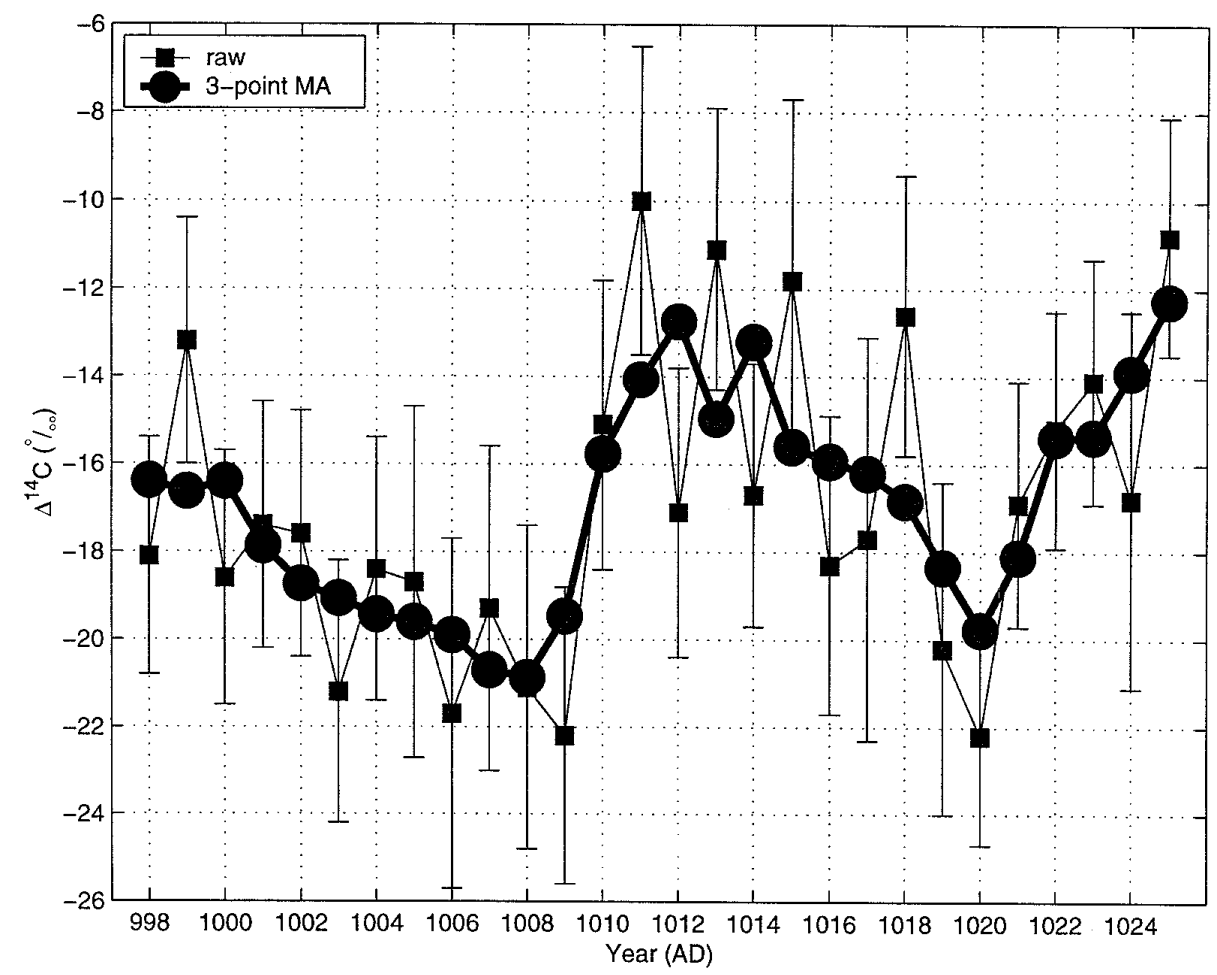

Figure $5 \Delta^{14} \mathrm{C}$ pulse due to $\gamma$-ray arrival following the supernova first observed optically on 30 April 1006 AD. Note the very fast rise time (only $3 \mathrm{yr}$ to maximum level). The ${ }^{14} \mathrm{C}$ data were obtained by AMS at $\pm 3 \%$ o precision.

\section{CONCLUSION}

We have come a long way since the fifth Radiocarbon Conference held at the University of Cambridge in 1962. It was at this conference that the ${ }^{14} \mathrm{C}$ community first became aware of the need for calibration of the ${ }^{14} \mathrm{C}$ time scale. Thirty-eight years later, after much labor by dendrochronologists and radiocarbon calibrators, we now have a calibration based on analysis of tree rings that reaches back 11,854 yr. All ${ }^{14} \mathrm{C}$ measurements have been obtained by high-precision beta counting. A combination of varve data and U-Th and AMS measurements on coral carry the calibration back to 15,000 BP. Preceding 15,000 BP, linear approximations stretch the coral calibration back to 24,000 BP. More work on coral calibration is of the utmost importance not only for dating but also for a better understanding of the climate record and the role of climate in the carbon cycle as witnessed by the inverse correlation between $\Delta^{14} \mathrm{C}$ and $\delta^{18} \mathrm{O}$ during the $\mathrm{B} \emptyset$ lling and Younger Dryas involving large changes in both $\Delta^{14} \mathrm{C}$ and $\delta^{18} \mathrm{O}$.

We restricted the use of INTCAL98 for Fourier analysis to the period from 7195 BC to avoid large gaps in the record (20-50 yr) prior to 7195 BC. Hopefully, it will be possible to fill these gaps. For other reasons discussed, the INTCAL98 data is not ideal for Fourier analysis. Nevertheless, the results are quite gratifying as can be seen in Figure 3.

There is information in the hyperfine structure of the $\Delta^{14} \mathrm{C}$ variations that can only be observed in high-precision single-year data. This includes high frequency components of the solar cycle as can 
be seen in Figure 4. Such data can reveal information concerning the arrival of $\gamma$-rays from a supernovae explosion as shown in Figure 5.

Also, the field of space physics, the study of radiation disturbances in space which is referred to as space weather, is becoming increasingly important. For example, a single solar flare can shut down an electrical grid, cause losing track of a fleet of Earth orbiting satellites or even cause the death of an astronaut outside the shelter of the Earth's magnetic field. If there were, as we believe, giant solar flares or sets of solar flares in the past that can be detected in ${ }^{14} \mathrm{C}$ records (Damon et al. 1989; Peristykh and Damon 1995, 1999), single-year data will be required.

Moreover, it appears that coastal upwelling of deep ocean water releasing nutrients and ${ }^{14} \mathrm{C}$ depleted $\mathrm{CO}_{2}$ is time dependent. Times of extremely high upwelling, sufficient to change the ${ }^{14} \mathrm{C}$ content of a prevailing air mass, could be dampened in decadal or bidecadal data. Ekman transport is wind driven and so interesting climate changes could be missed. In addition, single-year data can be merged into decadal data yielding increased precision.

\section{ACKNOWLEDGMENTS}

This paper has received support from NSF Grants ATM-9819228 and EAR-9730699, and the University of Arizona.

\section{REFERENCES}

Aschenbach B. 1998. Discovery of a young nearby supernova remnant. Nature 396(6707):141-2.

Bard E, Arnold M, Fairbanks RG, Hamelin B. 1993. ${ }^{230} \mathrm{Th}-{ }^{234} \mathrm{U}$ and ${ }^{14} \mathrm{C}$ ages obtained by mass spectrometry on corals. Radiocarbon 35(1):191-9.

Bard E, Arnold M, Hamelin B, Tisnerat-Laborde N, Cabioch G. 1998. Radiocarbon calibration by means of mass spectrometric ${ }^{230} \mathrm{Th}-{ }^{234} \mathrm{U}$ and ${ }^{14} \mathrm{C}$ ages of corals: an updated database including samples from Barbados, Mururoa and Tahiti. Radiocarbon 40(3):1085-92.

Becker B. 1993. An 11,000-year German oak and pine dendrochronology for radiocarbon calibration. Radiocarbon 35(1):201-13.

Bennett CL, Beukens RP, Clover MR, Gove HE, Liebert RB, Litherland AE, Purser KH, Sondheim WE. 1977. Radiocarbon dating using electrostatic accelerators: negative ions provide the key. Science 198(4316): 508-10.

Berezinskii VS, Ginzburg VL. 1990. Astrophysics of cosmic rays. Amsterdam and New York: North-Holland.

Braziunas TF, Fung IY, Stuiver M. 1995. The preindustrial atmospheric ${ }^{14} \mathrm{CO}_{2}$ latitudinal gradient as related to exchanges among atmospheric, oceanic, and terrestrial reservoirs. Global Biogeochemical Cycles 9(4): 565-84.

Broecker WS. 1991. The great ocean conveyor. Oceanography 4(2):79-89.

Broecker WS, Olson EA. 1959. Lamont radiocarbon measurements VI. American Journal of Science, Radiocarbon Supplement 1:111-32.

Burr GS, Beck JW, Taylor FW, Recy J, Edwards RL, Cabioch G, Correge T, Donahue DJ, O’Malley JM. 1998.
A high-resolution radiocarbon calibration between 11,700 and 12,400 calendar years BP derived from ${ }^{230} \mathrm{Th}$ ages of corals from Espiritu Santo Island, Vanuatu. Radiocarbon 40(3):1093-105.

Cadzow JA. 1987. Foundations of digital signal processing and data analysis. New York: Macmillan.

Cook ER, Peters K. 1981. The smoothing spline: a new approach to standardizing forest interior tree-ring width series for dendroclimatic studies. Tree-Ring Bulletin 41:45-53.

Damon PE. 1987. The history of the calibration of radiocarbon dates by dendrochronology. In: Aurenche O, Evin J, Hours F, editors. Chronologies in the Near East: relative chronologies and absolute chronology 16,000-4,000 B.P. Lyon, France: BAR International Series 379, Archaeological Series 3. p 61-104.

Damon PE. 1995. A note concerning "Location-dependent differences in the ${ }^{14} \mathrm{C}$ content of wood" by McCormac et al. Radiocarbon 37(2):829-30.

Damon PE, Burr G, Peristykh AN. 1999. $\Delta^{14} \mathrm{C}$ and Ekman transport, spiral and west coast upwelling. In: Storohmaier B, compiler. 8th International Conference on Accelerator Mass Spectrometry, Vienna, Austria, 6-10 September, 1999, Conf. Compendium. Vienna, Austria. p 101.

Damon PE, Burr G, Peristykh AN, Jacoby GC, D’Arrigo RD. 1996. Regional radiocarbon effect due to thawing of frozen earth. Radiocarbon 38(3):597-602.

Damon PE, Cheng S, Linick TW. 1989. Fine and hyperfine structure in the spectrum of secular variations of atmospheric ${ }^{14}$ C. Radiocarbon 31(3):704-18.

Damon PE, Dai K, Kocharov GE, Mikheeva IB, 
Peristykh AN. 1995. Radiocarbon production by the gamma-ray component of supernova explosions. $R a$ diocarbon 37(2):599-604.

Damon PE, Eastoe CJ, Hughes MK, Kalin RM, Long A, Peristykh AN. 1998. Secular variation of $\Delta^{14} \mathrm{C}$ during the Medieval Solar Maximum: a progress report. $R a-$ diocarbon 40(1):343-50.

Damon PE, Jirikowic JL. 1992a. Solar forcing of global climate change?. In: Taylor RE, Long A, Kra RS, editors. Radiocarbon after four decades: an interdisciplinary perspective. New York: Springer-Verlag. $\mathrm{p}$ 117-29.

Damon PE, Jirikowic JL. 1992b. The Sun as a low-frequency harmonic oscillator. Radiocarbon 34(2):199_ 205.

Damon PE, Lerman JC, Long A, Bannister B, Klein J, Linick TW. 1980. Report on the workshop on the calibration of the radiocarbon time scale. Radiocarbon 22(3):947-9.

Damon PE, Long A. 1962. Arizona radiocarbon dates III. Radiocarbon 4:239-49.

Damon PE, Long A, Sigalove JJ. 1963. Arizona radiocarbon dates IV. Radiocarbon 5:283-301.

Damon PE, Peristykh AN. 1999. Solar cycle length and 20th century Northern Hemisphere warming: revisited. Geophysical Research Letters 26(16):2469-72.

Damon PE, Sonett CP. 1991. Solar and terrestrial components of the atmospheric ${ }^{14} \mathrm{C}$ variation spectrum. In: Sonett CP, Giampapa MS, Matthews MS, editors. The Sun in time. Tucson: University of Arizona Press. p 360-88.

Dansgaard W, Johnsen SJ, Calusen HB, Dahl-Jensen D, Gundestrup NS, Hammer CU, Hvidberg CS, Steffensen JP, Sveinbjornsdottir AE, Jouzel J, Bond G. 1993. Evidence for general instability of past climate from a 250-kyr ice-core record. Nature 364(6434): 218-20.

De Jong AFM, Mook WG, Becker B. 1979. Confirmation of the Suess wiggles: 3200-3700 BC. Nature 280(5717):48-9.

De Vries H. 1958. Variation in concentration of radiocarbon with time and location on Earth. Koninklijke Nederlandse Akademie van Wetenschappen. Proceedings, Series B 61:94-102.

De Vries H. 1959. Measurement and use of natural radiocarbon. In: Abelson PH, editor. Researches in geochemistry. New York: John Wiley \& Sons. p 169-89.

Eddy JA. 1976. The Maunder Minimum. Science 192(4245):1189-202.

Eddy JA. 1977. Climate and the changing sun. Climatic Change 1(2):173-90.

Giordano AA, Hsu FM. 1985. Least square estimation with applications to digital signal processing. New York: Wiley.

Gleissberg W. 1944. A table of secular variations of the solar cycle. Terrestrial Magnetism and Atmospheric Electricity 49(4):243-4.
Godwin H. 1962. Radiocarbon dating: fifth international conference. Nature 195(4845):943-5.

Goslar T, Arnold M, Bard E, Kuc T, Pazdur MF, RalskaJasiewiczowa M, Rozanski K, Tisnerat N, Walanus A, Wicik B, Wieckowski K. 1995. High concentration of atmospheric ${ }^{14} \mathrm{C}$ during the Younger Dryas cold episode. Nature 377(6548):414-7.

Hughen KA, Overpeck JT, Lehman SJ, Kashgarian M, Southon JR, Peterson LC. 1998. A new ${ }^{14} \mathrm{C}$ calibration data set for the last deglaciation based on marine varves. Radiocarbon 40(1):483-94.

Iyudin AF, Schonfelder V, Bennett K, Bloemen H, Diehl R, Hermsen W, Lichti GG, Van der Meulen RD, Ryan J, Winkler C. 1998. Emission from ${ }^{44} \mathrm{Ti}$ associated with a previously unknown Galactic supernova. $\mathrm{Na}$ ture 396(6707):142-4.

Jirikowic JL, Damon PE. 1994. The Medieval Solar Activity Maximum. Climatic Change 26(2/3): 309-16.

Kennett JP. 1982. Marine geology. Englewood Cliffs, NJ: Prentice-Hall.

Klein J, Lerman JC, Damon PE, Linick TW. 1980. Radiocarbon concentration in the atmosphere: 8000-year record of variations in tree rings. First results of a USA workshop. Radiocarbon 22(3): 950-61.

Klein J, Lerman JC, Damon PE, Ralph EK. 1982. Calibration of radiocarbon dates: tables based on the consensus data of the Workshop on Calibrating the Radiocarbon Time Scale. Radiocarbon 24(2):103-50.

Lamb HH. 1965. The Early Medieval Warm Epoch and its sequel. Palaeogeography, Palaeoclimatology, Palaeoecology 1:13-37.

Lerman JC, Mook WG, Vogel JC. 1970. Radial translocation of carbon in bristlecone pine. In: Olsson IU, editor. Radiocarbon variations and absolute chronology. Stockholm: Almqvist \& Wiksell, p 275-301.

Lingenfelter RE, Ramaty R. 1970. Astrophysical and geophysical variation in $\mathrm{C} 14$ production. In: Olsson IU, editor. Radiocarbon variations and absolute chronology. Stockholm: Almqvist \& Wiksell. p 513-35.

Mann WB, Marlow WF, Hughes EE. 1961. The half-life of carbon-14. International Journal of Applied Radiation and Isotopes 11(2/3):57-67.

Murdin P. 1985. Supernovae. Cambridge and New York: Cambridge University Press.

Nelson DE, Korteling RG, Stott WR. 1977. Carbon-14: direct detection at natural concentrations. Science 198(4316):507-8.

Olsson IU, editor. 1970 Radiocarbon variations and $a b$ solute chronology. Proceedings of the 12th Nobel Symposium. Stockholm: Almqvist \& Wiksell.

Olsson IU, Karlén I, Turnbull AH, Prosser NJD. 1962. A determination of the half-life of ${ }^{14} \mathrm{C}$ with a proportional counter. Arkiv für Fysik 22(14):237-55.

Pearson GW, Pilcher JR, Baillie MGL, Hillam J. 1977. Absolute radiocarbon dating using a low altitude European tree-ring calibration. Nature 270(5632):25-8.

Pearson GW, Qua F. 1993. High-precision ${ }^{14} \mathrm{C}$ measure- 
ment of Irish oaks to show the natural ${ }^{14} \mathrm{C}$ variations from AD 1840-5000 BC: a correction. Radiocarbon 35(1): 105-23.

Peristykh AN, Damon PE. 1995. Cosmogenic isotope evidence of very high solar flare activity at the end of XIX century. Eos, Transactions, American Geophysical Union 76(46, Suppl):688.

Peristykh AN, Damon PE. 1999. Multiple evidence of intense solar proton events during solar cycle 13. In Kieda D, Salamon M, Dingus B, editors. 26th International Cosmic Ray Conference. Salt Lake City, 1999. Vol. 6. Salt Lake City. p 264-7.

Pestiaux P, Van der Mersch I, Berger A, Duplessy JC. 1988. Paleoclimatic variability at frequencies ranging from 1 cycle per 10000 years to 1 cycle per 1000 years: evidence for nonlinear behaviour of the climate system. Climatic Change 12(1):9-37.

Ralph EK, Stuckenrath R. 1960. Carbon-14 measurements of known age samples. Nature 188:185-7.

Reinsch CH. 1967. Smoothing by spline functions. $\mathrm{Nu}$ merische Mathematik 10:177-83.

Renfrew C. 1973. Before Civilization. New York: Knopf.

Schmidt B, Gruhle W. 1988. Klima, Radiokohlenstoffgehalt und Dendrochronologie. Naturwissenschaftliche Rundschau 41(5):177-82.

Spurk M, Friedrich M, Hofmann J, Remmele S, Frenzel B, Leuschner HH, Kromer B. 1998. Revisions and extension of the Hohenheim oak and pine chronologies: new evidence about the timing of the Younger Dryas/ Preboreal transition. Radiocarbon 40(3):1107-16.

Stuiver M, Becker B. 1993. High-precision decadal calibration of the radiocarbon time scale, AD 1950-6000 BC. Radiocarbon 35(1):35-66.

Stuiver M, Braziunas TF. 1993. Sun, ocean, climate and atmospheric $\mathrm{CO}_{2}$ : an evaluation of causal and spectral relationships. Holocene 3(4):289-305.

Stuiver M, Braziunas TF. 1998. Anthropogenic and solar components of hemispheric ${ }^{14} \mathrm{C}$. Geophysical Research Letters 25(3):329-32.
Stuiver M, Braziunas TF, Grootes PM, Zielinski GA. 1997. Is there evidence for solar forcing of climate in the GISP2 oxygen isotope record? Quaternary Research 48(3):259-66.

Stuiver M. Kra R, editors. 1986. Calibration Issue. Radiocarbon 28(2B).

Stuiver M, Long A, Kra R, editors. 1993. Calibration 1993. Radiocarbon 35(1).

Stuiver M, Reimer PJ. 1986. A computer-program for radiocarbon age calibration. Radiocarbon 28(2B): 1022-30.

Stuiver M, Reimer PJ, Bard E, Beck JW, Burr GS, Hughen KA, Kromer B, McCormac G, Van der Plicht J, Spurk M. 1998a. INTCAL98 radiocarbon age calibration, 24,000-0 cal BP. Radiocarbon 40(3):1041-83.

Stuiver M, Reimer PJ, Braziunas TF. 1998b. High-precision radiocarbon age calibration for terrestrial and marine samples. Radiocarbon 40(3):1127-51.

Stuiver M, Van der Plicht J. 1998. INTCAL98: Calibration Issue. Radiocarbon 40(3).

Suess HE. 1961. Secular changes in the concentration of atmospheric radiocarbon. Problems Related to Interplanetary Matter (Proceedings of the Informal Conference, Highland Park, Illinois. 20-22 June 1960). Washington DC: NAS-NRC Publication 845. p 90-5.

Vogel JC, Fuls A, Visser E, Becker B. 1993. Pretoria calibration curve for short-lived samples, 1930-3350 BC. Radiocarbon 35(1):73-85.

Watt DE, Ramsden D, Wilson HW. 1961. The half-life of carbon-14. International Journal of Applied Radiation and Isotopes 11(2/3):68-74.

Willis EH, Tauber H, Münnich KO. 1960. Variations in the atmospheric radiocarbon concentration over the past 1300 years. Radiocarbon 2:1-4.

Wohlfarth B. 1996. The chronology of the last termination: a review of radiocarbon-dated, high-resolution terrestrial stratigraphies. Quaternary Science Reviews 15(4):267-84. 